\title{
Use of Hemoadsorption in a Case of Severe Hepatic Failure and Hyperbilirubinemia
}

\author{
Andreas Faltlhauser Frank Kullmann \\ First Department of Internal Medicine, Kliniken Nordoberpfalz AG, Klinikum Weiden, \\ Weiden in der Oberpfalz, Germany
}

Dear Editor,

Acute severe hepatic failure associated with persistent severe hyperbilirubinemia is a rare but life-threatening critical illness typically affecting multiple other organs including renal and cerebral function [1]. We report the case of a 59-yearold male patient with medical history of lymphoblastic lymphoma, adipositas permagna (BMI 43), steatohepatitis, arterial hypertension, renal cysts, and a preceding laparoscopic cholecystectomy. After completion of therapy with rituximab and bendamustine for lymphoblastic lymphoma, the patient presented for a follow-up check at our hospital. With respect to the lymphoma, there was no evidence for remaining tumor activity. However, laboratory testing revealed significantly elevated transaminases (GOT $241 \mathrm{U} / \mathrm{L}, \mathrm{GPT} 196 \mathrm{U} / \mathrm{L}$ ) as well as increased total bilirubin serum levels $(2.3$ $\mathrm{mg} / \mathrm{dL}$ ), while retention parameters were within the normal range. In the further course, active hepatitis B was diagnosed (viremia $>100,000$ copies $/ \mathrm{mL}$ ) and therapy with entecavir was initiated. On day 9 after admission, the patient developed acute kidney injury [2] (oliguria $<0.2 \mathrm{~mL}$ / $\mathrm{kg} / \mathrm{h}$, creatinine $2.79 \mathrm{mg} / \mathrm{dL}$, Kidney Disease: Improving Global Outcomes [KEDIGO] level 3), and was admitted to the intensive care unit for escalation of therapy (application of maximum therapy, advanced monitoring and use of extracorporeal organ support). Continuous venovenous hemodiafiltration using re- gional citrate anticoagulation (Multifiltrate $\mathrm{CiCa}^{\circledR}, \mathrm{FMC}$, Bad Homburg, Germany) in combination with CytoSorb (CytoSorbents Inc., USA) added in predialyzer position was initiated to rebalance the excessive hyperbilirubinemia, hence to salvage kidney function at bilirubin levels reaching $39.5 \mathrm{mg} / \mathrm{dL}$ (GOT
988 U/L, GPT 792 U/L). This combined extracorporeal support was performed for 7 consecutive days. The course of laboratory findings during treatment is depicted in Figure 1. Bilirubin levels could be reduced from a maximum of 39.5-17.3 $\mathrm{mg} / \mathrm{dL}$ and continued to decrease in the following days. Notably, we were not able

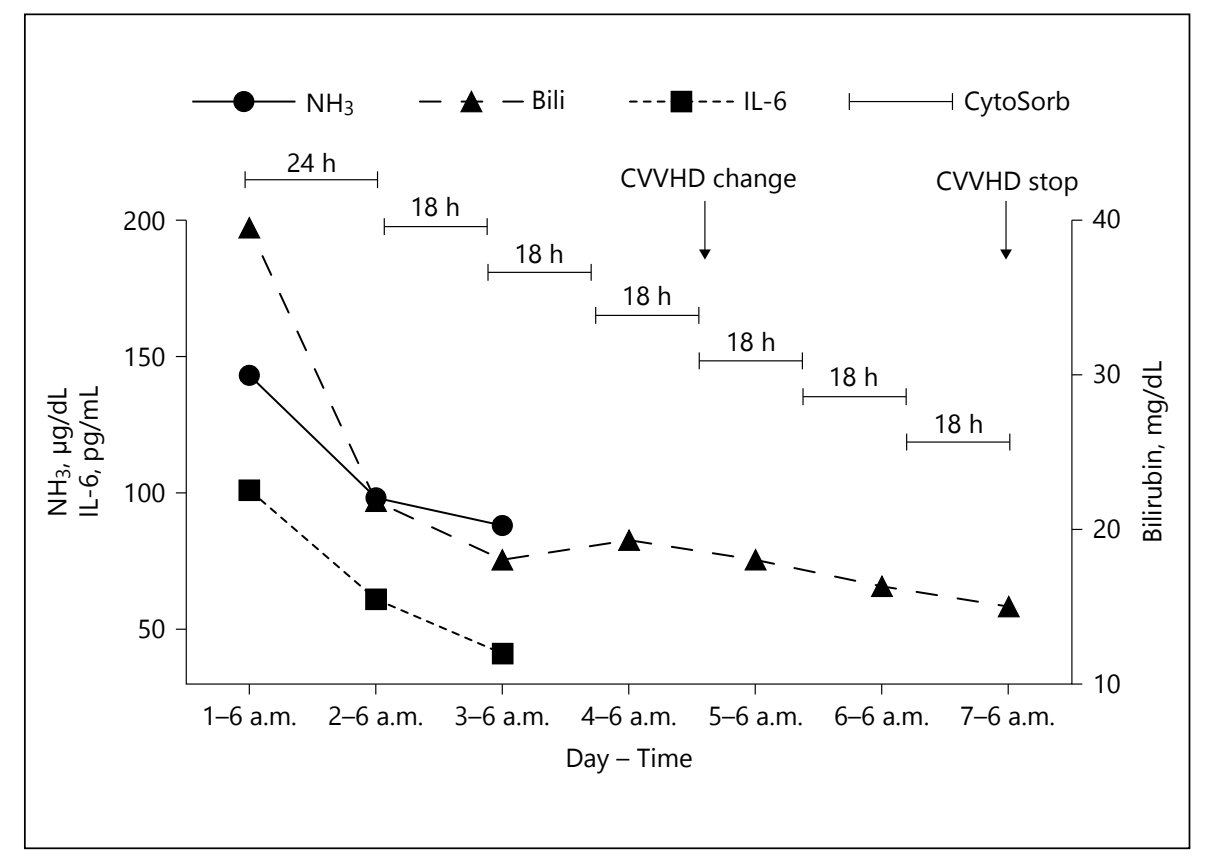

Fig. 1. Course of bilirubin, ammonia, and IL- 6 during the hemoadsorption treatment over 7 days.

\section{KARGER}

(c) 2017 S. Karger AG, Basel

E-Mail karger@karger.com

www.karger.com/bpu
Andreas Faltlhauser, MD, DEAA

First Department of Internal Medicine, Kliniken Nordoberpfalz AG

Klinikum Weiden, Söllnerstrasse 16

DE-92637 Weiden in der Oberpfalz (Germany)

E-Mail andreas.faltlhauser@ kliniken-nordoberpfalz.ag 
to reduce levels below $10 \mathrm{mg} / \mathrm{dL}$ and adsorber cartridges had be exchanged every $18 \mathrm{~h}$ as serum concentrations seemed to rebounce during treatment, which points towards a saturation of the hemoadsorption device. Liver transaminases continuously decreased until treatment day 7 (GOT $86 \mathrm{U} / \mathrm{L}, \mathrm{GPT} 73 \mathrm{U} / \mathrm{L}$ ) to values slightly elevated above the upper limit of normal. Initial hepatic encephalopathy (HE 2, CAM-ICU++) did completely resolve during the treatment period and $\mathrm{NH}_{3}$ levels decreased to normal levels. Values of IL- 6 during treatment diminished; however, the patient did not exhibit an acute inflammatory reaction at any time. Importantly, kidney function could not be improved considerably. After discontinuation of therapy, we observed a rebound in bilirubin levels to $20 \mathrm{mg} / \mathrm{dL}$. Three days after completion of therapy, liver and kidney function improved and urine output reached stable values of 0.4 $\mathrm{mL} / \mathrm{kg} / \mathrm{h}$ while still performing intermittent hemodialysis every $48 \mathrm{~h}$. However, despite intensified antiviral therapy in the further course, the deleterious progression of hepatitis B could not be stopped and the patient died within the next days. This is the first clinical case report describing the use of CytoSorb hemoadsorption during hyperbilirubinemic hepatic dysfunction due to active hepatitis $B$ infection. The treatment was safe and well tolerated. A decrease in bilirubin and IL-6 levels in combination with an improvement in hepatic encephalopathy are the main results to be drawn from this report. This is in line with several case reports [3-5]. In conjunction with similar previously published case reports, a controlled study examining the true effects of the device would be desirable.

\section{Disclosure Statement, Financial Support, and Informed Consent}

The authors declare that none of them has conflicts of interest associated with this report. Furthermore, there was no financial support for this study. Authors have declared that this study was performed in accordance to the research ethical guidelines. Informed consent to use clinical data for retrospective evaluation was obtained from the patient.
References

CytoSorb in Hyperbilirubinemia
1 Bernal W, Wendon J: Acute liver failure. N Engl J Med 2013;369:2525-2534.

2 Kidney Disease: Improving Global Outcomes (KDIGO) Acute Kidney Injury Work Group: KDIGO clinical practice guidelines for acute kidney injury. Kidney Inter Suppl 2012;2: 1138 .

3 Tomescu D, Dima SO, Tănăsescu S, Tănase CP, Năstase A, Popescu M: Effects of a novel cytokine haemoadsorbtion system on inflammatory response in septic shock after cephalic pancreatectomy - a case report. Romanian
Journal of Anaesthesia and Intensive Care 2014;21:134-138.

4 Tomescu DR, Olimpia Dima S, Ungureanu D, Popescu M, Tulbure D, Popescu I: First report of cytokine removal using CytoSorb ${ }^{\circledR}$ in severe noninfectious inflammatory syndrome after liver transplantation. Int J Artif Organs 2016;39:136-140.

5 Hinz B, Jauch O, Noky T, Friesecke S, Abel P, Kaiser R: CytoSorb, a novel therapeutic approach for patients with septic shock: a case report. Int J Artif Organs 2015;38:461-464. 